\title{
Large scale preparation of phycobiliproteins from Porphyra yezoensis using co-precipitation with ammonium sulfate
}

\author{
Chuner Cai, Chunxia Li, Shuxian Wu, Qing Wang, Ziye Guo, Peimin He* \\ Aquaculture and Life College, Shanghai Ocean University, Shanghai, China; ${ }^{*}$ Corresponding Author: pmhe2009@yahoo.cn
}

Received 26 June 2012; revised 28 July 2012; accepted 7 August 2012

\begin{abstract}
The purpose of this study was to extract phycobiliproteins (PBP) from Porphyra yezoensis using an optimized procedure and further establish a large scale process for protein production. According to our previous experiences on the extraction of PBP, salting out methods, e.g. ammonium sulfate precipitation, worked more efficiently than isoelectric precipitation, differential centrifugation or ultrafiltration. Thus, we chose ammonium sulfate to coprecipitate PBP in crude solution. After four times of precipitation followed by one time of high speed centrifugation, the maximum purity of crude phycoerythrin and phycocyanin reached $1.94\left(A_{565} / A_{280}\right)$ and $0.85\left(A_{615} / A_{280}\right)$, with a yield of $0.50 \%$ and $0.37 \%$, respectively. A total of $0.94 \mathrm{mg}$ phycoerythrin and $0.54 \mathrm{mg}$ phycocyanin with purity of more than 3.2 were obtained from $1 \mathrm{~g}$ dried $P$. yezoensis after additional chromatography. We further scaled up the frozen dried $P$. yezoensis from 20

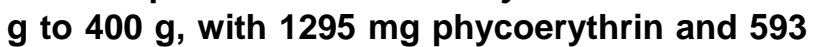
mg phycocyanin obtained.
\end{abstract}

Keywords: Porphyra yezoensis; Phycoerythrin; Phycocyanin; Ammonium Sulfate Precipitation; Hydroxylapatite

\section{INTRODUCTION}

Phycobiliproteins (PBP), including phycoerythrin (PE), phycocyanin (PC) and allo-phycocyanin (APC), are the main light-harvesting chromoproteins in a certain type of marine algae, which are water-soluble with bright color and characteristic fluorescence [1]. According to studies from the past 70 years, PBP are traditionally used as natural color additives in foods, maquillage, health products, pharmaceuticals, textiles, detergents and fountain $[2,3]$. Currently, PBP are mainly used as fluorescent probes that are expensive after commercialization $[4,5]$. Furthermore, the effects of PBP on anti-oxidation, antitumor, anti-virus, anti-inflammation, liver-protection, neuro-protection, UV protection, atherosclerosis and skin function activating have been demonstrated [6-9]. Recent studies indicated that PBP even have potential applications on enhancement of memory and disposal of optics message, fast photoelectricity detection and manual nerve network $[10,11]$.

The prices of highly purified PBP reached $\$ 5000$ $\$ 30,000 / g$ [5] which resulted in many studies contributing to improve the efficiency of PBP purification in the past half century. The routine process for PBP extraction contains three steps: cell disruption, primary isolation and column chromatographic purification [12]. In these procedures, $33 \mathrm{~g}$ PC and $2.3 \mathrm{~g}$ APC with purity of 3.4 and 4.0 respectively were obtained from $550 \mathrm{~g}$ Microcystis aeruginosa using DEAE-sepharose chromatography column [13]. Using hydrophobic chromatography, $98 \mathrm{mg}$ PE with a purity of 4.4 were obtained from $700 \mathrm{~g}$ Gracilaria verrucosa [14], $67 \mathrm{mg}$ PE with a purity of 3.5 from $550 \mathrm{~g}$ Palmaria palmate [15], and $23 \mathrm{mg}$ PE with a purity of 4.8 from $15 \mathrm{~g}$ Porphyra haitanensis [16]. Recently, novel techniques such as immuno-absorption and genetic recombination have been utilized for purification of PBP. For example, PC was selectively bound by polyclonal antibody prepared from mice and purified after elution using red light [17]. On the other hand, recombinant PC was generated through affinity tags adding, oligomerization and biospecific domains recognition [18]. Moreover, some simple and convenient techniques have been developed to produce a few quantity of PBP for analysis [19-21].

Immunoabsorption and genetic recombination were difficult to popularize due to their high costs and complex operation. In addition, in routine process the quality of products varies according with raw materials [22]. For example, hydrophobic chromatography was proved to be unsuitable for the purification of PBP from $P$. yezoensis [23]. Furthermore, routine methods have bottlenecks, e.g., 
high cost, long cycle and low yield in column chromatographic purification step. In this study, we improved the crude isolation step in the routine process and then utilized this improved procedure to purify PBP in a large scale from $P$. yezoensis, which is one of China's major cultural seaweeds

\section{MATERIALS AND METHODS}

\subsection{Materials}

P. yezoensis was collected from sea area in Lvsi, Jiangsu Province. Alga was washed with fresh water and then stored at $-20^{\circ} \mathrm{C}$ for future uses.

\subsection{Comparasion of PBP Preparation with Ammonium Sulfate}

$200 \mathrm{~g}$ frozen $P$. yezoensis was chopped into pieces and immersed in $50 \mathrm{mmol} / \mathrm{L}$ sodium phosphate buffer containing $1 \mathrm{mmol} / \mathrm{L}$ EDTA (PBSE, pH 6.8) at ratio $(\mathrm{g} / \mathrm{mL})$ of 1:5 (P. yezoensis: buffer). After sitting statically overnight, pieces of $P$. yezoensis were homogenized and centrifuged (Supra centrifuge, Hanil Science Corporation, Incheon, South Korea) at $10,000 \mathrm{~g}$ for $15 \mathrm{~min}$ at $4^{\circ} \mathrm{C}$. The $980 \mathrm{ml}$ supernatants were collected in which $420 \mathrm{ml}$ solution ( 7 gradients $\times 3$ parts/concentration $\times 20 \mathrm{ml} /$ part) was precipitated with different ammonium sulfate concentrations: $15 \%, 20 \%, 25 \%, 3 \%, 35 \%, 40 \%, 45 \%$. After precipitation, the supernatant was collected separately and each supernatant was divided into three parts. The concentrations of ammonium sulfate for three parts were set at $50 \%, 55 \%$ and $60 \%$. The overnight precipitation was collected by centrifugation. The pellet was dissolved in PBSE. The spectra of solution at each step were measured using Ultrospec 2000 spectrophotometer (Pharmacia Biotech Inc., Piscataway, NJ) to calculate the purity and content of PBP.

The remained $560 \mathrm{ml}(980 \mathrm{ml}-420 \mathrm{ml})$ supernatants was dealt with twice precipitation $(20 \%$ ammonium sulfate concentrations in first precipitation while $50 \%$ secondly) and the pellet was dissolved in $280 \mathrm{ml}$ PBSE, from which $100 \mathrm{ml}$ solution was divided into five parts averagely and the gradients of ammonium sulfate were set at $5 \%, 10 \%, 15 \%, 20 \%$ and $25 \%$. The supernatants overnight were collected with purity and yield determined.

The remained $180 \mathrm{ml}(280 \mathrm{ml}-100 \mathrm{ml})$ supernatants was dealt with the third ammonium sulfate precipitation at $10 \%$ concentration, from which $100 \mathrm{ml}$ solution was divided into five parts averagely and the gradients were set at $20 \%, 25 \%, 30 \%, 35 \%$ and $40 \%$. The precipitant overnight were collected to determine the purity and yield.

\subsection{Large Scale Preparation of PBP}

PBP was extracted from $1 \mathrm{~g}, 20 \mathrm{~g}$ or $400 \mathrm{~g}$ frozen $P$. yezoensis respectively with four times of ammonium sulfate precipitation described above. Then, the final precipitant was dissolved in $50 \mathrm{mM}$ phosphate buffer and desalted with sephadex G-25 (GE Co. USA) and further purified with selfmade-hydroxyapatite (HAP) [24]. By gradient eluting using a series of phosphate buffer $(\mathrm{pH}$ 6.8) with different concentrations, the eluent containing $\mathrm{PE}$ and PC were collected, respectively. The whole procedure was monitored by protein absorption using Ultrospec 2000 spectrophotometer.

\subsection{Spectral and SDS-PAGE Analysis of PBP}

The purified PE and PC were scanned by F-4500 fluorescence spectrophotometer (Hitachi Company, Japan) followed by SDS PAGE using 14\% separating and $5 \%$ stacking gel.

\subsection{PE and PC Purity}

PE purity was monitored from the $\mathrm{A}_{565} / \mathrm{A}_{280}$ ratio. PC purity was monitored from the $\mathrm{A}_{615} / \mathrm{A}_{280}$ ratio. Absorbance at $565 \mathrm{~nm}$ and $615 \mathrm{~nm}$ indicate the maximum PE and $\mathrm{PC}$ absorption respectively, while at $280 \mathrm{~nm}$, it is due to the concentration of proteins in solution (Liu et al. 2005).

\subsection{PE and PC Concentration}

$\mathrm{PE}$ and $\mathrm{PC}$ concentration was calculated in $\mathrm{mg} \cdot \mathrm{mL}^{-1}$ by absorbance at 565, 615 and $650 \mathrm{~nm}$, using the Gao formula (Gao 1993):

$$
\begin{aligned}
& \mathrm{C}_{\mathrm{PE}}=0.123 \mathrm{~A}_{565}-0.068 \mathrm{~A}_{615}+0.015 \mathrm{~A}_{650} \\
& \mathrm{C}_{\mathrm{PC}}=0.162 \mathrm{~A}_{615}-0.001 \mathrm{~A}_{565}-0.098 \mathrm{~A}_{650}
\end{aligned}
$$

\subsection{PE and PC Yield}

PE yield $=\left(\mathrm{C}_{\mathrm{PE}}\right.$ after purification $\times$ volume after purification $) /\left(\mathrm{C}_{\mathrm{PE}}\right.$ before purification $\times$ volume before purification $) \times 100 \%$.

$\mathrm{PC}$ yield $=\left(\mathrm{C}_{\mathrm{PC}}\right.$ after purification $\times$ volume after purification $) /\left(\mathrm{C}_{\mathrm{PC}}\right.$ before purification $\times$ volume before purification) $\times 100 \%$.

\section{RSULTS}

Influence of ammonium sulfate precipitation on the yield and purity of PBP.

In trivial test, the purity of PE after twice precipitations exceeded 0.8 in the group in which the ammonium sulfate concentration in the first precipitation step was between $15 \%$ and $25 \%$. The variation of yield and purity 
for PC under different concentrations of ammonium sulfate was similar to those for PE (Figure 1). After the third times of precipitation, the yield and purity of $\mathrm{PE}$ was similar to those of PC in each concentration except for $25 \%$ of ammonium sulfate (Figure 2). However, the yield of both proteins after the fourth precipitation was increased with the increasing concentration of ammonium sulfate. The maximum purity for both proteins was achieved at 35\% ammonium sulfate (Figure 3).

\subsection{Large Scale Extraction of PBP}

A total of $0.94 \mathrm{mg}$ phycoerythrin and $0.54 \mathrm{mg}$ phycocyanin with a purity of higher than 3.2 were obtained from $1 \mathrm{~g}$ dried $P$. yezoensis after chromatography. And $1295 \mathrm{mg}$ phycoerythrin and $593 \mathrm{mg}$ phycocyanin were obtained furtherly after scaling up the raw material from $20 \mathrm{~g}$ to $400 \mathrm{~g}$ (Table 1).

\subsection{Spectral and SDS-PAGE Analysis of PBP}

Solution and dry powder of purified PE and PC after hydroxyapatite chromatography were prepared. The maxim-um emission peaks of PE and PC were at $575 \mathrm{~nm}$ and $650 \mathrm{~nm}$, with maximum excitation peaks among 530 - $570 \mathrm{~nm}$ and $600-650 \mathrm{~nm}$, respectively (Figure 4).
SDS PAGE analysis showed that both PE and PC were highly pure with main subunits' molecular weight of about $18 \mathrm{kD}$ for PE, and about $19 \mathrm{kD}$ for PC (Figure 5).

\section{Discussion}

\subsection{Primary Isolation of PBP from $P$. yezoensis}

According to the routine process of protein extraction, improvement of primary isolation may increase the efficiency of column chromatographic purification. Ammonium sulfate precipitation was often applied in primary isolation and divided into three patterns according to previous reports. The first pattern named "one step precipitation" was used by Zheng et al. to achieve a $60 \%$ final ammonium sulfate concentration in crude protein extract. With this pattern, a purity of 0.42 of PE was obtained from Bangia fusco-purpurea [25]. The second pattern was designated as "continual precipitations" in which PE, PC and APC from Rhodophyceae or Cyanobacteria were isolated at an amonium sulfate concentration of $25 \%, 35 \%$ and $60 \%$, respectively [24]. However, PC and APC could not be isolated from Spirulina at the ammonium sulfate concentration of $30 \%$ or $50 \%$ [26]. Based on Figure 2, it was also difficult to identify an appropriate concentration to distinctly isolate the two

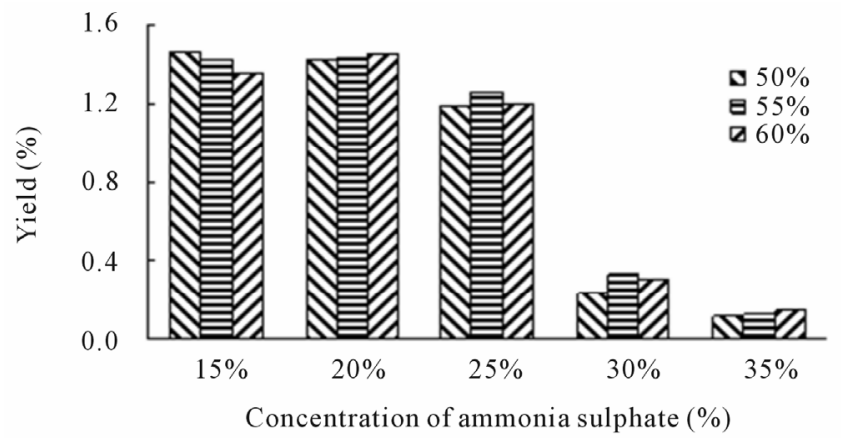

(a)

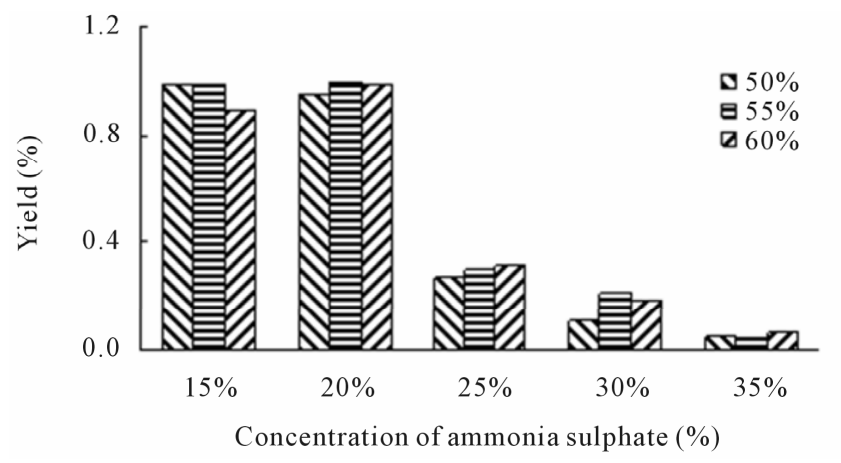

(c)

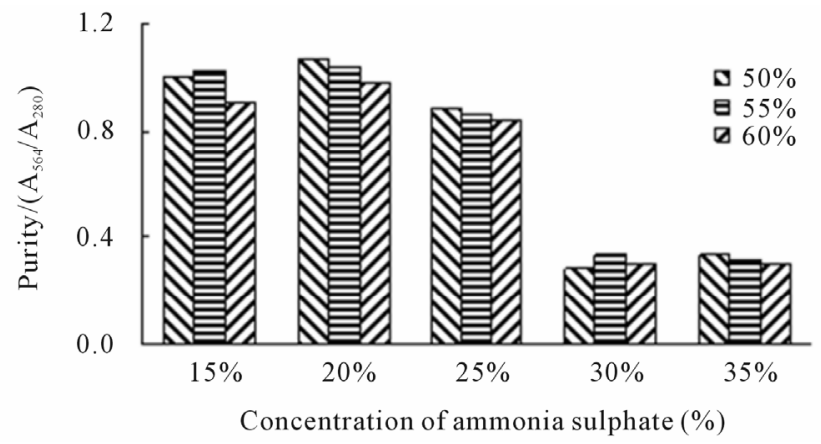

(b)

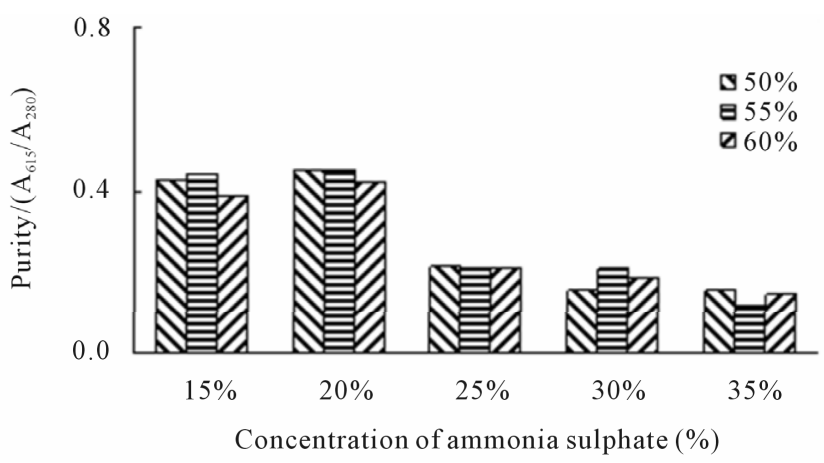

(d)

Figure 1. Purity and yield of both PE and PC from P. yezoensis by twice precipitation with ammonia sulfate. (a) Yield of PE crude extract; (b) Purity of PE crude extract; (c) Yield of PC crude extract; (d) Purity of PC crude extract. X-axis: concentration of ammonium sulfate; Y-axis in (a) and (c): Yield of the protein; Y-axis in (b) and (d): Purity of the protein. 


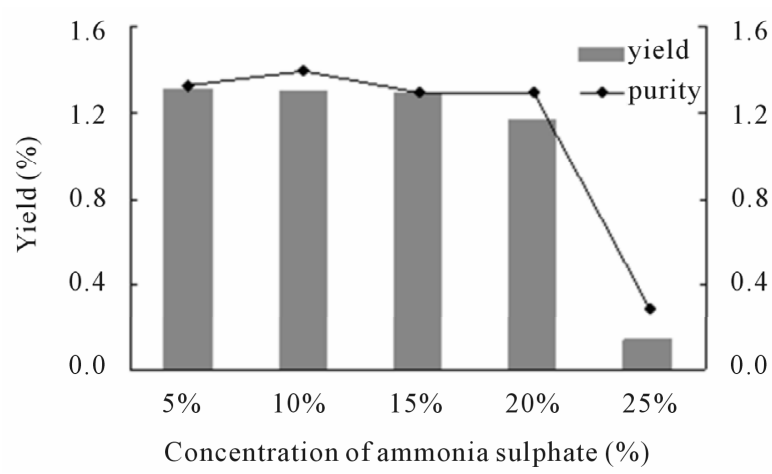

(a)

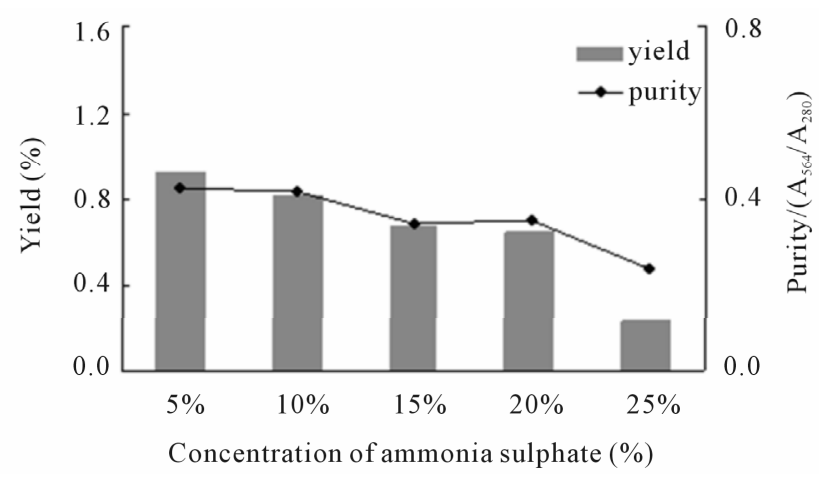

(b)

Figure 2. Purity and yield of both PE and PC from P. yezoensis by third precipitation with ammonia sulfate. (a) Purity and yield of PE crude extract; (b) Purity and yield of PC crude extract. X-axis: concentration of ammonium sulfate; Y-axis: Purity and yield of the protein.

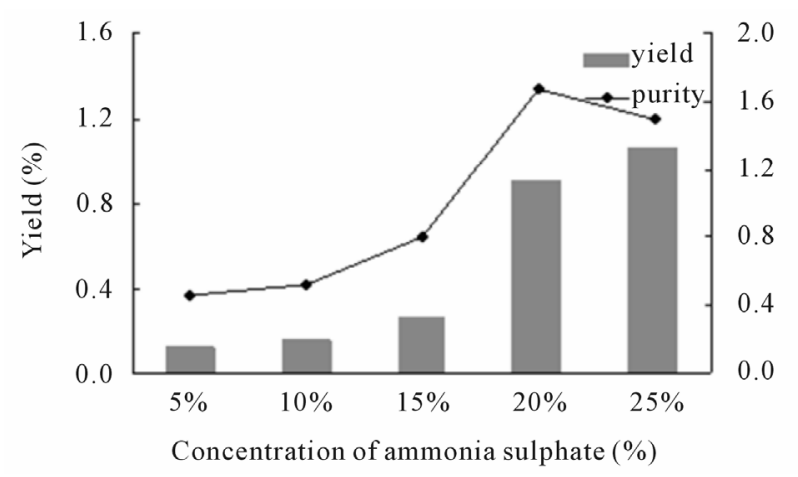

(a)

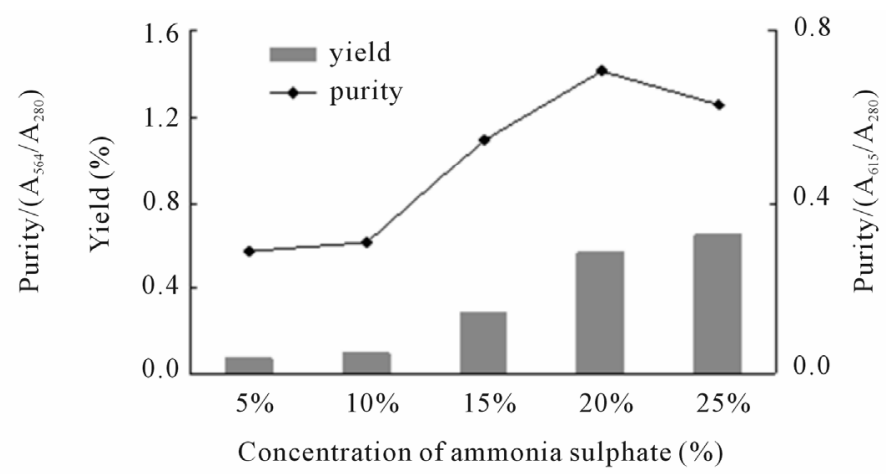

(b)

Figure 3. Purity and yield of both PE and PC from P. yezoensis by fourth precipitation with ammonia sulfate. (a) Purity and yield of PE crude extract; (b) Purity and yield of PC crude extract. X-axis: concentration of ammonium sulfate; Y-axis: Purity and yield of the protein.

Table 1. The quantity and yield of phycobiliproteins (purity is over 3.2) in Porphyra yezoensis.

\begin{tabular}{ccccc}
\hline \multirow{2}{*}{ Input $(\mathrm{g})$} & \multicolumn{2}{c}{ Output (mg) } & \multicolumn{2}{c}{ Yield (\%) } \\
\cline { 2 - 5 } & PE & PC & PE & PC \\
\hline 1 & 0.94 & 0.54 & 0.094 & 0.054 \\
20 & 33.04 & 21.73 & 0.165 & 0.109 \\
400 & 1295.2 & 593.06 & 0.323 & 0.148 \\
\hline
\end{tabular}

proteins. The third pattern titled "divided precipitation" was used to extract PC and APC from Sp (NS) 90020 using $25 \%$ - $55 \%$ of ammonium sulfate. The concentrations were then decreased in the steps afterwards. Purified PC $\left(\mathrm{A}_{615} / \mathrm{A}_{280}=3.7\right)$ and $\operatorname{APC}\left(\mathrm{A}_{615} / \mathrm{A}_{280}=1.1\right)$ was obtained after 9 times of precipitation [27]; however, it was difficult to control the slight concentration changes, e.g., from $28 \%$ to $32 \%$ or from $35 \%$ to $48 \%$.

In this study, after two times of ammonium sulfate precipitations, the yields did not change any more when the six concentration combinations (including 15\% and
$20 \%$ at the first step and $50 \%, 55 \%$ and $60 \%$ at the second step) were applied. For saving of reagents, we chose combination with $20 \%$ in the first step and $50 \%$ in the second step to increase the purity. In the third step, we used five concentration gradients from $5 \%$ to $25 \%$, and the results indicated that the maximal purity of PE (1.40) was achieved at the concentration of $10 \%$, while the yield of PC $(0.92 \%)$ reached maximum at the concentration of $5 \%$. As the yield of PE was much higher than that of PC in this process, we chose $10 \%$ of ammonium sulfate in this step. After the fourth precipitation, both proteins achieved maximal purity at concentration of 35\% $(\mathrm{PE}=1.67, \mathrm{PC}=0.71)$ and maximal yield at concentration of $40 \%(\mathrm{PE}=1.06 \%, \mathrm{PC}=0.65 \%)$. In order to get more products, we chose $40 \%$ concentration in this step.

Besides ammonium sulfate, precipitation regents used in primary isolation include active carbon [28] and rivanol [29]. Therefore, we have used active carbon to absorb impurities in 8 http://www.iciba.com/grads/ gradients' solutions in which the active carbon to protein ratios $(\mathrm{g} / \mathrm{L})$ ranged from $1: 1$ to $50: 1$, resulting in the 


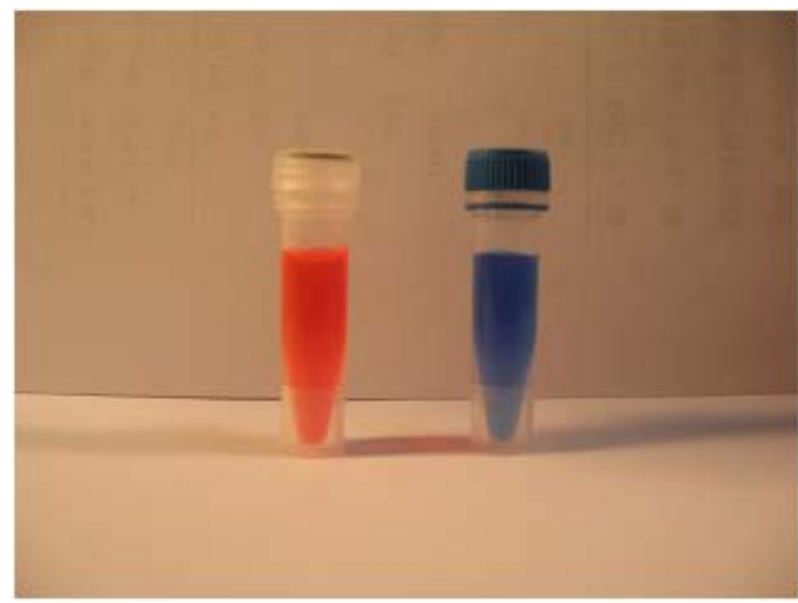

(a)

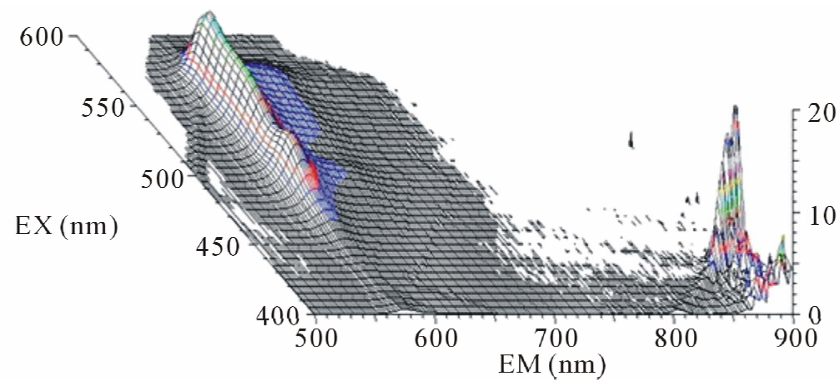

(c)

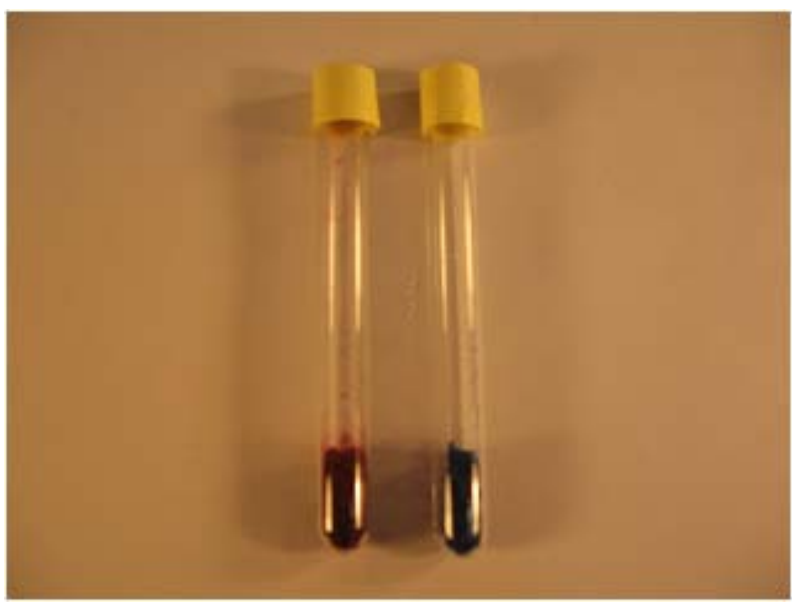

(b)

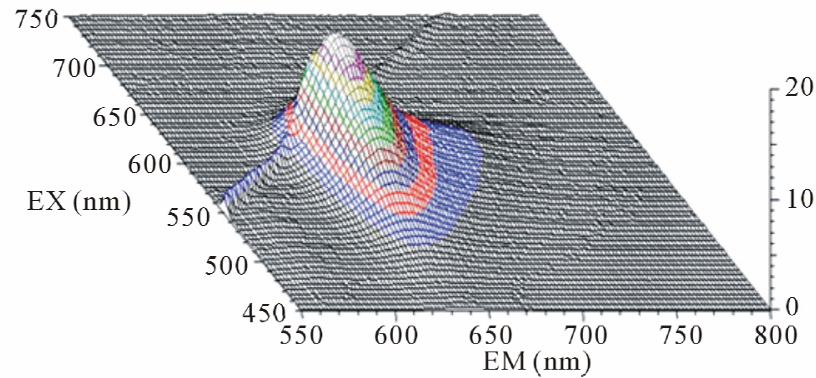

(d)

Figure 4. Photograph and florescence excite and emission spectra of the purified proteins. (a) Solution of PE and PC after hydroxyapatite chromatography; (b) Dry powder of PE and PC after hydroxyapatite chromatography; (c) Florescence excite and emission spectra of PE after hydroxyapatite chromatography; (d) Florescence excite and emission spectra of PC after hydroxyapatite chromatography.

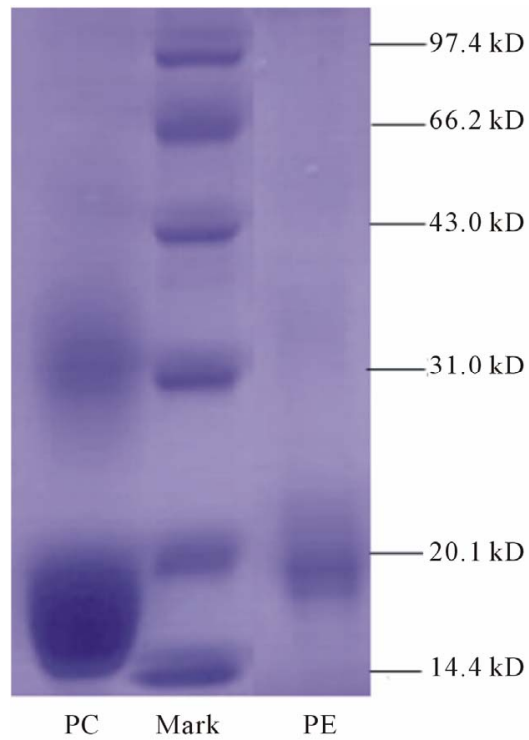

Figure 5. SDS PAGE analyses of $\mathrm{PC}$ and PE from P. yezoensis after hydro-xyapatite chromatography. Lane PC was loaded with purified PC, lane Mark was loaded with protein ladder and lane PE was loaded with purified PE. purity of $0.38-0.53$ and $0.16-0.22$, respectively, for $\mathrm{PE}$ and PC. Rivanol was more widely utilized according to previous reports. It was applied to isolate PBP from Porphyridium cruentum [30] and Nostoc sp [31]. CPC with purity of 3.90 and 3.00 from Spirulina (Arthrospira) fusiformis [32] and Arthronema africanum [29], respectively, were purified after fractional precipitation with rivanol. So we designed to use rivanol to absorb im- purities in 5 gradients' solutions in which rivanol to protein ratios $(\mathrm{g} / \mathrm{g})$ ranged from $1: 10$ to $16: 10$, and achieved a purity of 0.56 and 0.28 for $\mathrm{PE}$ and $\mathrm{PC}$, respectively. These results were in contrast with previous reports showing that rivanol could remove polysaccharide sharply from solutions [30]. Our results indicated that precipitations with other reagents, e.g., active carbon and rivanol did not contribute to the purification of phycobiliproteins from $P$. yezoensis.

In addition to precipitation, other methods have been used to isolate PBP based on its isoelectric point at $\mathrm{pH}$ $3.9-4.5$ and stable state at $\mathrm{pH} 6.8$ at $4^{\circ} \mathrm{C}$. We normally place the crude extract from $P$. yezoensis at a continuous $\mathrm{pH}$ range from 3.9 to $4.4(0.1 \mathrm{pH}$ interval between every two $\mathrm{pH}$ points), which resulted in a purity of $0.3-0.4$ 
and 0.2 for PE and PC, respectively. The crude extract was precipitated with $45 \%$ ammonium sulfate, followed by differential centrifugation from $1000 \mathrm{~g}$ to $11,000 \mathrm{~g}$ (2000 g interval between every two centrifugation). However, these steps could not separate target proteins from impurities. The crude extracts precipitated with $45 \%$ ammonium sulfate were divided into several parts and adjusted each part to different $\mathrm{pH}$ ranging from 4.8 to $10.3(0.5 \mathrm{pH}$ interval between every two $\mathrm{pH}$ points $)$ followed by centrifugation at $10,000 \mathrm{~g}$. The results indicated that the purity of PE and PC presents as a parabolic curve and the maximum purity appeared at $\mathrm{pH} 6.8$. The solution containing protein with the highest purity (1.35) was then placed at increasing temperature points ranging from $25^{\circ} \mathrm{C}$ to $45^{\circ} \mathrm{C}\left(5^{\circ} \mathrm{C}\right.$ interval between every two temperatures) and still the purity was nearly unchanged. Ultrafiltration was often applied in the later steps of primary protein isolation [33]. We showed in this study that the purities of PE and PC from P. yezoensis in the extracted solutions were increased from 0.9 to 1.4 or 0.5 to 0.7 , respectively, when ultrafiltration was utilized. These results were consistent with previous research using ultrafiltration sartocon, e.g., vivo 200 or vivo 50. However, filter membrane is easily blocked by big molecules such as polysaccharide and has nonspecific absorptions, which prevents the wide application of ultrafiltration. Furthermore, ultrafiltration sartocon usually costs high.

In summary, protein precipitation using ammonium sulfate during primary isolation had an advantage over methods of isoelectric point, differential centrifugation and ultrafiltration. This paper has provided an appropriate procedure for ammonium sulfate precipitation in isolation of PBP from P. yezoensis.

\subsection{Large Scale Preparation of PBP from P. yezoensis}

Many types of procedures and materials were used for large scale preparation of PBP [13-16] and the latest approach was the application of hydrophobic chromatography. For example, $28 \mathrm{~g} P$. yezoensis was smashed and applied to phenyl-sepharose column to obtain $27 \mathrm{mg} \mathrm{PE}$ with a purity of $2.0-2.5$. After purification with another DEAE-sepharose column, $23 \mathrm{mg} \mathrm{PE}$ with a purity of 4.5 was obtained [23]. In this study, we applied $400 \mathrm{~g} P$. yezoensis and extracted $1292 \mathrm{mg} \mathrm{PE}$ and $592 \mathrm{PC}$ with purity above 3.2 after one time of chromatography. More importantly, we used self-made hydroxyapatite, which was cheaper than phenyl-sepharose and DEAE-sepharose.

The mechanisms of the method used in this paper were described as follows. Firstly, the principle of ammonium sulfate precipitation is similar to that of hydrophobic chromatography. Both methods are based on the con- formation change of proteins under high salt concentration and consequent non-covalent aggregation of hydrophobic groups, which separates proteins from hydrophilic molecules. Secondly, the effect of repeated ammonium sulfate precipitation is similar to that of repeated hydrophobic chromatography. Thirdly, centrifugation and desalination can remove extremely large and small molecules, which is similar to gel filtration chromatography. Finally, hydroxyapatite had special stereochemical structure. This special structure is capable of selectively binding proteins based on following four factors: electrostatic interaction, formation of covalent complex substance, repulsive interaction and geometric distribution of charges [34]. Therefore, the production of highly purified PBP by only one step of separation with hydroxyapatite chromatography was benefited from the optimized primary isolation procedure as mentioned above.

It has been reported that $\mathrm{PE}$ from $P$. yezoensis has two peaks at $498 \mathrm{~nm}$ and $565 \mathrm{~nm}$ in absorption spectrum [23] and its characteristic fluorescence emission peak is at $576 \mathrm{~nm}$. The peak of absorption spectrum of PC is at 615 $\mathrm{nm}$ [35] and the fluorescence emission peak is between $630 \mathrm{~nm}$ and $642 \mathrm{~nm}$ [36]. The experimental results are in agreement with the above characteristics.

\subsection{Social and Ecological Benefits of This Method}

The method developed in this study had good economic benefits due to the cheap seaweed ( $P$. yezoensis costs 3.0 US Dollars $/ \mathrm{kg}$ in the market), reagent (ammonium sulfate cost 2.3 US Dollars/kg in the market) and hydroxyapatite (made by ourselves), as well as high yield and purity of target proteins obtained, which has the potential to purify PBP in large scale.

Large scale production of PBP needs a great amount of $P$. yezoensis, which favors the mariculturists. It is said that marine economy has occupied large portion of China's national economy, while there are many problems which inflict pain on the fisherfolks. For example, the breeding area was gradually reduced, the processing technologies were backward, and problems associated with degradation of fishery resources and transferring still existed. $P$. yezoensis culturing, which costs low, may help to improve the income of fisherfolks.

Culturing $P$. yezoensis will benefit not only the fisherfolks, but also the pollution control around sea areas. We have investigated the ability and efficiency of large-scale $P$. yezoensis cultivation in the removal of inorganic nitrogen and phosphorus from open sea areas [37]. That study was conducted from 2002 to 2004 , in a 300 ha nori farm along the Lvsi coast, Qidong County, Jiangsu Province, China, where P. yezoensis was harvested to 
extract PBP in the current study. Compared to the control area, $P$. yezoensis farming resulted in the reduction of $\mathrm{NH}_{4}-\mathrm{N}, \mathrm{NO}_{2}-\mathrm{N}, \mathrm{NO}_{3}-\mathrm{N}$ and $\mathrm{PO}_{4}-\mathrm{P}$ by $50 \%-94 \%, 42 \%-$ $91 \%, 21 \%-38 \%$ and $42 \%-67 \%$, respectively. In $2003-$ 2004 , an average of $14708.5 \mathrm{~kg}$ of tissue nitrogen and $2373.5 \mathrm{~kg}$ of tissue phosphorus in $P$. yezoensis biomass were harvested annually from 300 ha of cultivation from Lvsi coastal water. These results indicated that $P$. yezoensis efficiently removed excessive nutrients from nearshore eutrophic coastal areas. Therefore, large-scale cultivation of $P$. yezoensis could alleviate eutrophication in coastal waters economically.

In conclusion, a procedure were developed concluding four times of ammonium sulfate precipitation plus HA chromatography to extract PBP from $P$. yezoensis. This method has potential of scale up and $1295 \mathrm{mg}$ phycoerythrin and $593 \mathrm{mg}$ phycocyanin were obtained from $400 \mathrm{~g}$ frozen material.

\section{ACKNOWLEDGEMENTS}

This research was financially supported by the National Science and Technology Support Program (2012BAC07B03) and Shanghai Education Committee of China (Preponderant Subject Program\# S30701).

\section{REFERENCES}

[1] Liu, L.N., Chen, X.L., Zhang, X.Y., Zhang, Y.Z. and Zhou, B.C. (2005) One-step chromatography method for efficient separation and purification of R-phycoerythrin from Polysiphonia urceolata. Journal of Biotechnology, 116, 91-100. doi:10.1016/j.jbiotec.2004.09.017

[2] Dufosséa, L., Galaupa, P., Yaronb, A., Aradb, S.M., Blancc, P., Murthyd, K.N.C. and Ravishankard, G.A. (2005) Microorganisms and microalgae as sources of pigments for food use: A scientific oddity or an industrial reality? Trends in Food Science \& Technology, 16, 389406. doi:10.1016/j.tifs.2005.02.006

[3] Santiago-Santos, M.C., Ponce-Noyola, T., Olvera-RamIrez, R., Ortega-López, J. and Cañizares-Villanueva, R.O. (2004) Extraction and purification of phycocyanin from Calothrix sp. Process Biochemistry, 39, 2047-2052. doi:10.1016/i.procbio.2003.10.007

[4] Kronick, M.N. and Grossman, P.D. (1983) Immunoassay techniques with fluorescent phycobiliprotein conjugates. Clinical Chemistry, 29, 1582-1586.

[5] Sekar, S. and Chandramohan, M. (2008) Phycobiliproteins as a commodity: Trends in applied research, patents and commercialization. Journal of Applied Phycology, 20, 113-136. doi:10.1007/s10811-007-9188-1

[6] Benedetti, S., Benvenuti, F., Pagliarani, S., Francogli, S., Scoglio, S. and Canestrari, F. (2004) Antioxidant properties of a novel phycocyanin extract from the blue-green alga Aphanizomenon flos-aquae. Life Sciences, 75, 23532362. doi:10.1016/j.lfs.2004.06.004

[7] Cai, X.H., Zheng, S., He, L.M. and Jiang, J.L. (1995)
Study on promotion of laser therapy for carcinoma using phycocyanin from Spirulina. Chinese Journal of Marine Drugs, 12, 290-291.

[8] Nagaoka, S., Shimizu, K., Kaneko, H., Shibayama, F., Morikawa, K., Kanamaru, Y., Otsuka, A., Hirahashi, T. and Kato, T. (2005) A novel protein C-phycocyanin plays a crucial role in the hypocholesterolemic action of Spirulina platensis concentrate in rats. The Journal of Nutrition, 135, 2425-2430.

[9] Shih, C.M., Cheng, S.N., Chih-Shung Wong Kuo, Y.L. and Chou, T.C. (2009) Antiinflammatory and antihyperalgesic activity of C-phycocyanin. Anesthesia \& Analgesia, 108, 1303-1310. doi:10.1213/ane.0b013e318193e919

[10] Burrows, S.M. Patel, P. and Pappas, D. (2009) Light tolerance of R-phycoerythrin and a tandem conjugate observed by single molecule recrossing events. Applied Spectroscopy, 63, 709-715. doi: $10.1366 / 000370209788559737$

[11] Womick, J.M. and Moran, A.M. (2009) Nature of excited states and relaxation mechanisms in C-phycocyanin. The Journal of Physical Chemistry B, 113, 15771-15782. doi:10.1021/jp908093x

[12] Sun, L., Wang, S., Gong, X., Zhao, M., Fu, X. and Wang, L. (2009) Isolation, purification and characteristics of R-phycoerythrin from a marine macroalga Heterosiphonia japonica. Protein Expression and Purification, 64, 146-154. doi:10.1016/j.pep.2008.09.013

[13] Padgett, M.P. and Krogmann, D.W. (1987) Large scale preparation of pure phycobiliproteins. Photosynthesis Research, 11, 225-235. doi:10.1007/BF00055062

[14] Wang, G.C. (2002) Isolation and purification of phycoerythrin from red alga Gracilaria verrucosa by expanded-bed-adsorption and ion-exchange chromatography. Chromatographia, 56, 509-513.

[15] Wang, G.C., Sun, H.B., Fan, X. and Tseng, C.K. (2002) Large-scale isolation and purification of R-phycoerythrin from red alga Palmaria palmata using the expanded bed adsorption method. Journal of Integrat Plant Biology, 44, 541-546.

[16] Niu, J.F., Wang, G.C., Zhou, B.C., Lin, X.Z. and Chen, C.S. (2007) Purification of R-phycoerythrin from Porphyra haitanensis (Bangiales, Rhodophyta) using expanded-bed absorption. Journal of Phycology, 43, 13391347.

[17] Keiller, D.R., Whitelam, G.C. and Smith, H. (1988) Polyclonal antibodies raised to phycocyanins contain components specific for the red-absorbing form of phytochrome. Planta, 176, 391-398. doi:10.1007/BF00395420

[18] Cai, Y.A., Murphy, J.T., Wedemayer, G.J. and Glazer, A.N. (2001) Recombinant phycobiliproteins: Recombinant C-phycocyanins equipped with affinity tags, oligomerization, and biospecific recognition domains. Analytical Biochemistry, 290, 186-204.

[19] Št'astná, M., Radko, S. and Chrambach, A. (2000) Separation efficiency in protein zone electrophoresis performed in capillaries of different diameters. Electrophoresis, 21, 985-992.

[20] Viskari, P.J. and Colyer, C.L. (2002) Separation and 
quantitation of phycobiliproteins using phytic acid in capillary electrophoresis with laser-induced fluorescence detection. Journal of Chromatography A, 972, 269-276. doi:10.1016/S0021-9673(02)01085-3

[21] Viskaria, P.J. and Colyer, C.L. (2003) Rapid extraction of phycobiliproteins from cultured cyanobacteria samples. Analytical Biochemistry, 319, 263-271. doi:10.1016/S0003-2697(03)00294-X

[22] Ranjitha, K. and Kaushik, B.D. (2005) Purification of phycobiliproteins from Nostoc muscorum. Journal of Scientific and Industrial Research, 64, 372-375.

[23] Niu, J.F., Chen, Z.F., Wang, G.C. and Zhou, B.C. (2009) Purification of phycoerythrin from Porphyra yezoensis Ueda (Bangiales, Rhodophyta) using expanded bed absorption. Journal of Applied Phycology, 22, 25-31.

[24] Siegelman, H. and Kycia, J. (1978) Algal biliproteins: Handbook of phycological method. Cambridge University Press, Cambridge, 71-79.

[25] Zheng, J., Gao, Y.H., Wang, W.X. and Huang, S.Y. (2003) Studies on crude extraction methods of phycoerythrin from Bangia fusco-purpurea and denaturalization mechanism of phycobiliprotein in different irradiation conditions. Journal of Xiamen University (Natural Science), 42, 117-122.

[26] Peng, W., Shang, S., Liu, G., Fu, Y. and Wu, Q. (1999) Extraction of phycobiliprotein from Spirulina platensis (Sp,-D). Food Science, 20, 48-49.

[27] Hu, Y., Hu, H., Li, Y. and Geng, Y. (2002) Study on mass production of phycobilins from PC rich strain of Spirulina platensis. Journal of Wuhan Botanical Research, 20, 299-302.

[28] Cohen, Z., Reungjitchachawali, M., Siangdung, W. and Tanticharoen, M. (1993) Production and partial purification of $\gamma$-linolenic acid and some pigments from Spirulina platensis. Journal of Applied Phycology, 5, 109-115. doi:10.1007/BF02182428

[29] Minkova, K., Tchorbadjieva, M., Tchernov, A., Stojanova, M., Gigova, L. and Busheva, M. (2007) Improved procedure for separation and purification of Arthronema africanum phycobiliproteins. Biotechnology Letters, 29, 647651. doi:10.1007/s10529-006-9274-5
[30] Tcheruov, A.A., Minkova, K.M., Georgiev, D.I. and Houbavenska, N.B. (1993) Method for B-phycoerythrin purification from Porphyridium cruentum. Biotechnology Techniques, 7, 853-858. doi:10.1007/BF00156361

[31] Tchernova, A.A., Minkovab, K.M., Houbavenskab, N.B. and Kovachevac, N.G. (1999) Purification of phycobiliproteins from Nostoc sp. by aminohexyl-sepharose chromatography. Journal of Biotechnology, 69, 69-73. doi:10.1016/S0168-1656(98)00206-5

[32] Minkova, K.M., Tchernov, A.A., Tchorbadjieva, M.I., Fournadjieva, S.T., Antova, R.E. and Busheva, M.C. (2003) Purification of C-phycocyanin from Spirulina (Arthrospira) fusiformis. Journal of Biotechnology, 102, 55-59. doi:10.1016/S0168-1656(03)00004-X

[33] Reisa, A., Mendesb, A., Lobo-Fernandesa, H., Empisb, J.A. and Novaisb, J.M. (1998) Production, extraction and purification of phycobiliproteins from Nostoc sp. Bioresource Technology, 66, 181-187. doi:10.1016/S0960-8524(98)00064-9

[34] Sudarsanan, K. and Young, R.A. (1969) Significant precision in crystal structural details. Holly Springs hydroxyapatite. Acta Crystallographica Section B Structural Crystallography and Crystal Chemistry, 25, 1534-1543. doi:10.1107/S0567740869004298

[35] Pu, Y., Jiang, L. and Zeng, F. (1986) Preparation of allophycocyanin and studies on the characteristics of allophycocyanin from Porphyra haitanesis. Science Bulletin, 4, 272-274.

[36] Grabowski, J. and Gantt, E. (1978) Photophysical properties of phycobiliproteins from phycobilisomes: Fluorescence lifetimes, quantum yields, and polarization spectra. Photochemstry and Photobiology, 28, 39-45. doi:10.1111/j.1751-1097.1978.tb06927.x

[37] He, P.M., Xu, S., Zhang, H., Wen, S., Dai, Y., Lin, S. and Yarish, C. (2008) Bioremediation efficiency in the removal of dissolved inorganic nutrients by the red seaweed, Porphyra yezoensis, cultivated in the open sea. Water Research, 42, 1281-1289. doi:10.1016/j.watres.2007.09.023 